\title{
Current limiting performance of transformer-type superconducting fault current limiter made of BSCCO and REBCO wires
}

\section{$\operatorname{AUTHOR}(S):$}

Yonemura, N.; Yamabe, K.; Shirai, Y.; Kobayashi, S.; Nagaishi, T.; Konishi, M.

\section{CITATION:}

Yonemura, N.... [et al]. Current limiting performance of transformer-type superconducting fault current limiter made of BSCCO and REBCO wires. IEEE Transactions on Applied Superconductivity 2015, 25(3): 5601104.

\section{ISSUE DATE:}

2015-06

URL:

http://hdl.handle.net/2433/228375

\section{RIGHT:}

(C) 2015 IEEE. Personal use of this material is permitted. Permission from IEEE must be obtained for all other uses, in any current or future media, including reprinting/republishing this material for advertising or promotional purposes,

creating new collective works, for resale or redistribution to servers or lists, or reuse of any copyrighted component of this work in other works.; This is not the published version. Please cite only the published version.; この論文は出版社版 でありません。引用の際には出版社版をご確認ご利用ください。 


\title{
Current limiting performance of transformer type Superconducting Fault Current Limiter made of BSCCO and REBCO wires
}

\author{
N. Yonemura, K. Yamabe, Y. Shirai, Member, IEEE, S. Kobayashi, T. Nagaishi, and M. Konishi
}

\begin{abstract}
Superconducting Fault Current Limiters (SFCLs) are expected to be installed in the power system for fault current limitation and improvement of power system stability. Among various SFCLs, we have proposed the transformer type SFCL that produces limiting reactance for smaller fault currents and additionally gives limiting resistance for larger fault currents. Therefore, the transformer type SFCL shows better recovery performance than a resistive type SFCL. In this paper, we fabricated two transformer type SFCLs using different HighTemperature Superconducting (HTS) wires (Bi-2223 (BSCCO) wire and GdBCO, which is a kind of Rare-Earth-BariumCopper-Oxide (REBCO) wire) for the secondary coils and compared their current limiting characteristics. They were designed under the condition that the specifications of the primary coils and their trigger current level are about the same respectively. As a result of comparing their current limiting characteristics, the transformer type SFCL using GdBCO wire for the secondary coil shows a larger limiting reactance and dissipates less energy. Therefore, the transformer type SFCL using GdBCO wire for the secondary coil shows better recovery performance.
\end{abstract}

Index Terms-Bismuth compounds, Fault current limiters, High-temperature superconductors, Rare earth compounds, Short-circuit currents, Superconducting coils

\section{INTRODUCTION}

$\mathrm{W}$ HEN numerous distributed generators are interconnected with the power system, the short-circuit current level will exceed the rated capacity of circuit breakers. Furthermore, the large short-circuit current could break electric power equipment series-connected to the power system. Nowadays, current limiting reactors are introduced and substation busses are split to reduce the short-circuit current. However, they could deteriorate power system stability. In such circumstances, Superconducting Fault

Manuscript received August 4, 2014; accepted November 3, 2014. Date of publication June 1, 2015; date of current version November 28, 2014.

N. Yonemura and Y.Shirai are with Graduate School of Energy Science, Kyoto University, Kyoto 606-8501, Japan, e-mail: yonemura@pe.energy.kyoto-u.ac.jp; shirai.yasuyuki.7v@kyoto-u.ac.jp.

K. Yamabe was with Graduate School of Energy Science, Kyoto University, Kyoto 606-8501, Japan, e-mail: yamabe@ @e.energy.kyoto-u.ac.jp.

S. Kobayashi is with Superconductivity Technology Division, Sumitomo Electric Industries, Ltd., Osaka 554-0024, Japan, email: kobayashishinichi@sei.co.jp.

T. Nagaishi and M. Konishi are with Advanced Superconductor Development Group Power System R\&D Center, Sumitomo Electric Industries, Ltd., Osaka 554-0024, Japan, email: nagaishi@sei.co.jp; konishimasaya@ sei.co.jp.
Current Limiters (SFCLs) are installed in several areas [1]-[3]. SFCLs are the superconducting power equipment, whose impedance is small in steady-state condition and large in fault condition. Therefore, SFCLs do not deteriorate power system stability in steady-state condition and effectively limit the short-circuit current in fault condition.

Among various SFCLs [4], a resistive type SFCL is popular because its system is simple and compact [5]. However, it requires long recovery time because the temperature of a superconductor rapidly rises during current limiting operation. SFCLs must recover after current limiting operation so as to operate for next fault. Then inductive type SFCLs have also studied frequently [6]-[8]. They dissipate less energy in fault condition due to the limiting reactance. Therefore, inductive type SFCLs show better recovery performance than a resistive type SFCL. Among inductive type SFCLs, we have proposed the transformer type SFCL that has both resistive and inductive impedance and is able to control its trigger current level by adjusting turn ratio [9]-[11].

In our previous studies, the transformer type SFCLs using only Bi-2223 (BSCCO) wire were fabricated [9]-[11] and current limiting tests of them have been conducted in our labscale power system [10],[11]. In this paper, two transformer type SFCLs using different High-Temperature Superconducting (HTS) wires (BSCCO wire or GdBCO wire) for the secondary coils were fabricated and their current limiting characteristics are compared.

\section{CONCEPT OF TRANSFORMER TYPE SFCL}

The transformer type SFCL has two co-axially coreless superconducting coils. The primary coil is wound on the Fiber Reinforced Plastics (FRP) pipe as solenoid shape and their terminals are connected in series to the power system. The secondary coil is wound on the primary coil in a similar way and short-circuited.

In steady-state condition, both coils are in the superconducting state and the current through the secondary coil is induced to cancel the magnetic flux of the primary coil. Therefore, the transformer type SFCL has slightly small leakage inductance. When the short-circuit current flows, the secondary coil wire turns to the normal state first. Trigger current is defined as primary coil current at this time. Due to the resistance of the secondary coil wire, induced current gets saturated and the magnetic flux of the primary coil is no longer cancelled enough. Therefore, the limiting reactance 
TABLE I

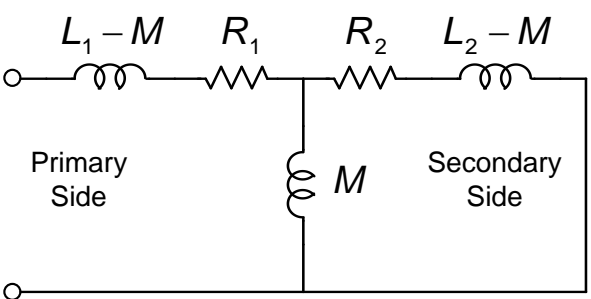

Fig. 1. Equivalent circuit of the transformer type SFCL. $L_{1}, L_{2}$, and $M$ are the primary coil inductance, the secondary coil inductance, and the mutual inductance respectively. $R_{1}$ and $R_{2}$ are the resistances of the primary coil and the secondary coil respectively.

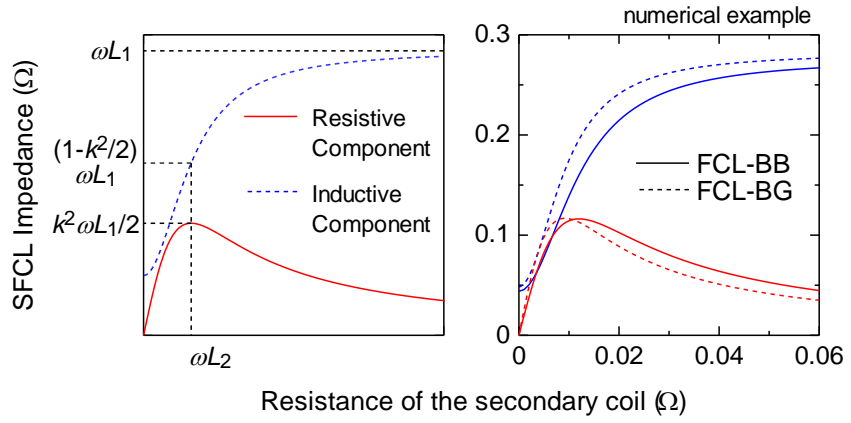

Fig. 2. Impedance of the transformer type SFCL as a function of secondary coil resistance $R_{2}$ at $R_{1}=0$. The larger the ratio $R_{2} / L_{2}$ is, the larger the inductive component. Right graph shows calculation results of two transformer type SFCLs designed in title III.

mainly appears at the power line terminal. When the shortcircuit current is much larger, the primary coil wire also turns to the normal state and the limiting resistance additionally appears. Therefore, the transformer type SFCL shows better recovery performance than a resistive type SFCL.

Fig. 1 shows the simplified equivalent circuit of the transformer type SFCL. The impedance $Z_{\mathrm{fcl}}$ of transformer type SFCL is calculated as

$$
Z_{\mathrm{fcl}}=\left(R_{1}+\frac{\omega^{2} M^{2} R_{2}}{R_{2}{ }^{2}+\omega^{2} L_{2}{ }^{2}}\right)+\mathrm{j} \omega\left(L_{1}-\frac{\omega^{2} M^{2} L_{2}}{R_{2}{ }^{2}+\omega^{2} L_{2}{ }^{2}}\right) .
$$

The real part and the imaginary part of (1) are the resistive and inductive component of the SFCL impedance respectively. Fig. 2 shows $Z_{\text {fcl }}$ as a function of $R_{2}$ at $R_{1}=0$. Fig. 2 indicates that the larger the ratio $R_{2} / L_{2}$ is, the larger the limiting reactance. Therefore, the transformer type SFCL has larger limiting reactance by using a $\mathrm{GdBCO}$ wire for the secondary coil because the normal state resistance of the $\mathrm{GdBCO}$ wire is generated more quickly and larger than that of the BSCCO wire. Therefore, we fabricated two transformer type SFCLs using different HTS wires (BSCCO or GdBCO) for the secondary coils and compare their current limiting characteristics.

\section{DESIGN OF DEMONSTRATION MOdel}

Two transformer type SFCLs using different HTS wires (BSCCO or GdBCO) for the secondary coils were fabricated. Table I shows the specifications of the BSCCO wire and the GdBCO wire. The BSCCO wire is wrapped with half-lapped $12.5 \mu \mathrm{m}$-thick polyimide insulation.
THE SPECIFICATIONS OF THE BSCCO WIRE AND THE GDBCO WIRE. BOTH WIRES WERE FABRICATED BY SUMITOMO ELECTRIC INDUSTRIES, LTD.

(a) The specification of the BSCCO wire

\begin{tabular}{cc}
\hline \hline Width & $3.8 \mathrm{~mm}$ \\
Total thickness & $0.34 \mathrm{~mm}$ \\
Cross-section ratio & $1: 1.6: 1.2$ \\
(BSCCO : Silver : Copper Alloy) & \\
Average critical current I c \\
$(1 \mu \mathrm{V} / \mathrm{cm}$ criterion, $77 \mathrm{~K})$ \\
$\begin{array}{c}\text { Average } n \text {-value } \\
(0.1-1 \mu \mathrm{V} / \mathrm{cm}, 77 \mathrm{~K})\end{array}$ \\
\hline \hline
\end{tabular}

(b) The specification of the GdBCO wire

\begin{tabular}{cc}
\hline \hline Width & $4.05 \mathrm{~mm}$ \\
Total Thickness & $0.17 \mathrm{~mm}$ \\
Copper, Silver, Nickel, SUS 316L $(\mu \mathrm{m})$ & $50,16,3,100$ \\
GdBCO, Intermediate layer $(\mu \mathrm{m})$ & $3,0.5$ \\
Average critical current Ic & $160 \mathrm{~A}$ \\
$(1 \mu \mathrm{V} / \mathrm{cm}$ criterion, 77 K) & \\
Average $n$-value & 34 \\
$(0.1-1 \mu \mathrm{V} / \mathrm{cm}, 77 \mathrm{~K})$ & \\
\hline \hline
\end{tabular}

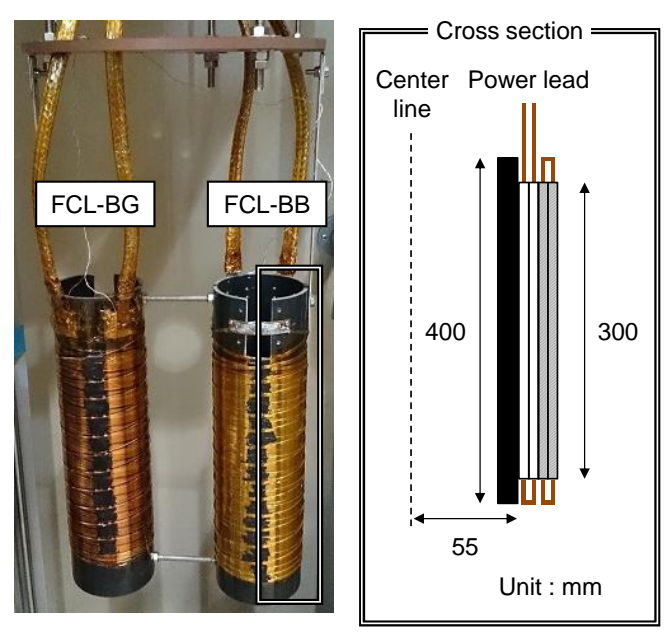

$\Longleftarrow$ Primary coil $\rightleftharpoons$ Secondary coil $\quad$ FRP pipe

Fig. 3. Photograph and cross-section diagram of the fabricated SFCLs. All coils have two layer windings. Each layer is insulated by polyimide tape.

The primary coils of both SFCLs are made of the BSCCO wire. The secondary coil of one SFCL is also made of the same BSCCO wire (hereafter called "FCL-BB"). The secondary coil of another SFCL is made of the GdBCO wire (here after called "FCL-BG"). The diameter and the height of the SFCLs are $110 \mathrm{~mm}$ and $300 \mathrm{~mm}$ to set them in the cryostat together. Though the secondary coils are wound on the primary coils, the SFCLs have enough cooling areas and the HTS wires immediately return to the superconducting state after current limiting operation.

Fig. 3 shows the photograph and the cross-section diagram of the SFCLs. Table II shows the specifications of the SFCLs. 
TABLE II

THE SPECIFICATIONS OF FCL-BB AND FCL-BG.

\begin{tabular}{ccc}
\hline \hline Parameter & FCL-BB & FCL-BG \\
\hline Primary coil wire & BSCCO & BSCCO \\
Secondary coil wire & BSCCO & GdBCO \\
Coil diameter $(\mathrm{mm})$ & 300 & 300 \\
Coil height $(\mathrm{mm})$ & 110 & 110 \\
Primary coil turns & $70+70$ & $70+70$ \\
Secondary coil turns & $15+14$ & $13+12$ \\
Primary inductance $(\mu \mathrm{H})$ & 732 & 748 \\
Secondary inductance $(\mu \mathrm{H})$ & 31.8 & 24.4 \\
Mutual inductance $(\mu \mathrm{H})$ & 144 & 129 \\
Primary wire length $(\mathrm{m})$ & 48.4 & 48.4 \\
Secondary wire length $(\mathrm{m})$ & 10 & 8.64 \\
Trigger current $(\mathrm{A})$ & 30.9 & 30.3 \\
Resistance of laminate material & 37.1 & 65.7 \\
in secondary coil wire at $77 \mathrm{~K}(\mathrm{~m} \Omega)$ & & \\
\hline \hline
\end{tabular}

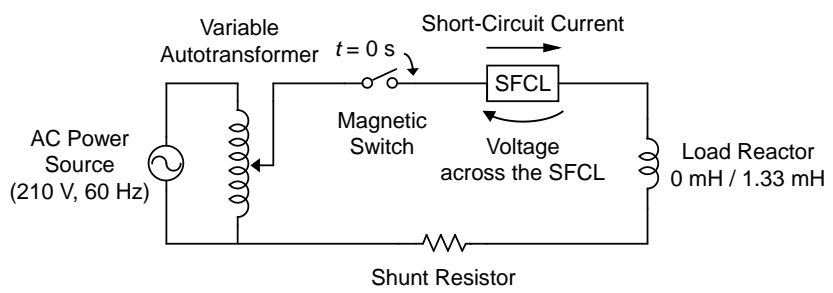

Fig. 4. Schematic diagram of the experimental circuit.

Two transformer type SFCLs have same trigger current so that their current limiting characteristics can be compared. The resistance of the laminate material in the GdBCO wire is larger than that in the BSCCO wire. The $n$-value of the GdBCO wire is higher than that of the BSCCO wire. The cross-section of the GdBCO wire is smaller than that of the BSCCO wire. Therefore, the GdBCO wire generates larger normal state resistance and FCL-BG has more limiting reactance.

\section{EXPERIMENTAL SETUP}

Fig. 4 shows the experimental circuit including a variable autotransformer that is able to produce variable level of voltage, a magnetic switch, the SFCL (FCL-BB or FCL-BG), a load reactor, and a shunt resistor. The inductance of the load reactor is $0 \mathrm{mH}$ or $1.33 \mathrm{mH}$. The SFCLs were immersed in liquid nitrogen. When the magnetic switch was closed at $t=0 \mathrm{~s}$, various short-circuit current flowed according to changing the voltage across the variable autotransformer.

The terminal voltage across the SFCL was measured. The current through the primary coil was measured by the shunt resistor. The current through the secondary coil was measured by a Rogowski coil. Furthermore, platinum resistance temperature sensors are put on the primary and secondary coils to measure their temperature changes. The resistance at zero degrees Celsius is about $100 \Omega$, the size is
$2.3 \mathrm{~mm} \times 2.0 \mathrm{~mm} \times 0.65 \mathrm{~mm}$, and the control current is $1 \mathrm{~mA}$.

\section{EXPERIMENTAL RESULT}

\section{A. Electric Performance Result}

Fig. 5 shows one of the experimental results. The voltage across the variable autotransformer is $105 \mathrm{~V}_{\mathrm{rms}}$ and the inductance of the load reactor is $1.33 \mathrm{mH}$. Figs. 5(a), 5(b), and 5(c) show the primary coil current, the secondary coil current, and the voltage across the SFCL in fault condition, respectively. FCL-BG has less induced current and it is expected that the magnetic flux of FCL-BG remains more than that of FCL-BB and FCL-BG has more limiting reactance in fault condition.

The fundamental waves of the experimental results for
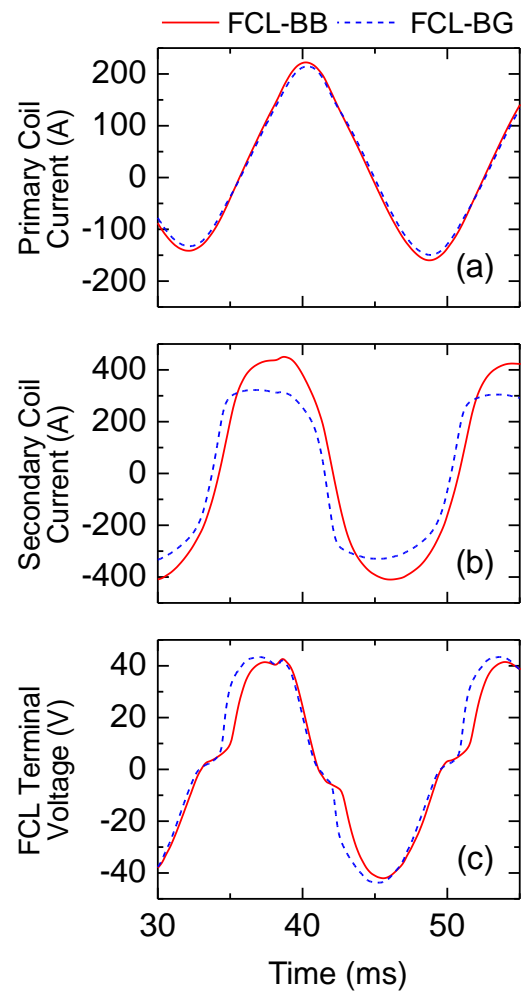

Fig. 5. An example of the experimental results in fault condition. The voltage across the variable autotransformer is $105 \mathrm{~V}_{\mathrm{rms}}$ and the inductance of a load reactor is $1.33 \mathrm{mH}$. (a) the current through the primary coil. (b) the current through the secondary coil. (c) the voltage across the SFCL.

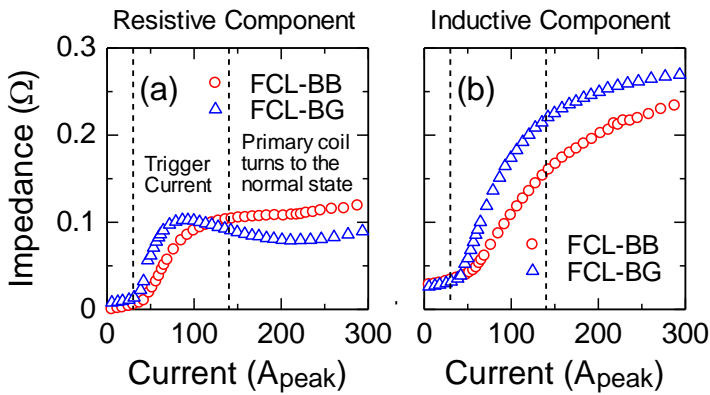

Fig. 6. SFCL impedance for the short-circuit current. (a) resistive component. (b) inductive component. 


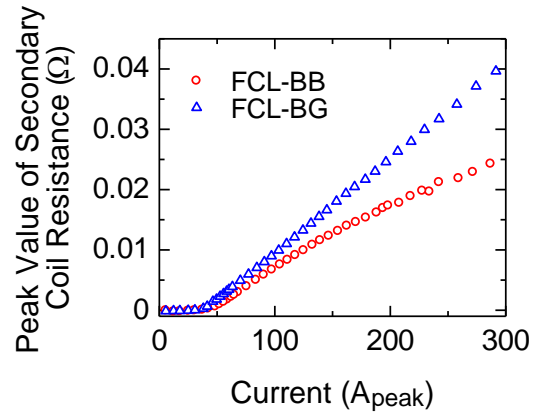

Fig. 7. The peak value of secondary coil resistance for the short-circuit current.
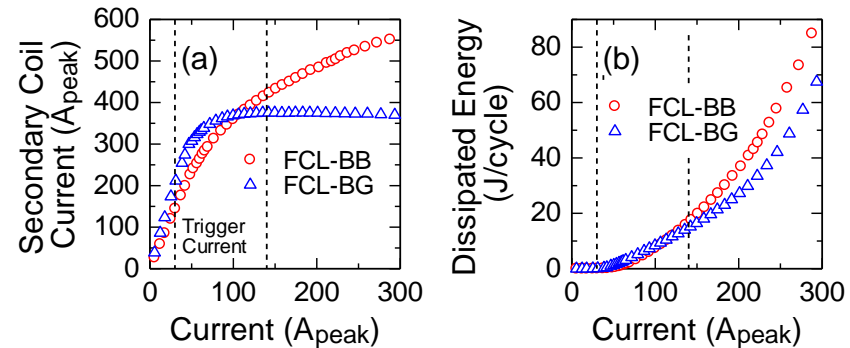

Fig. 8. (a) Current through the secondary coil for the short-circuit current. (b) Dissipated energy of the SFCLs during one cycle in fault condition for the short-circuit current.

various voltages across the variable autotransformer are calculated by the Fourier Transform and the limiting impedances of the SFCLs are estimated. Fig. 6 shows the limiting impedances for the current through the circuit. FCL$\mathrm{BG}$ has more limiting reactance.

Fig. 7 shows the peak value of secondary coil resistance for the short-circuit current. This is calculated from the equivalent circuit shown in Fig. 1. The secondary coil resistance of FCLBG is larger than that of FCL-BB.

Fig. 8(a) shows the current through the secondary coil for the short-circuit current. The current through the secondary coil of FCL-BG is saturated more quickly than that of FCL$\mathrm{BB}$ because the $\mathrm{GdBCO}$ wire turns to the normal state more quickly and generates larger resistance than the BSCCO wire. This result confirms that FCL-BG has more limiting reactance than FCL-BB.

Fig. 8(b) shows the dissipated energy of the SFCLs during one cycle in fault condition. FCL-BG, which has more limiting reactance, dissipates less energy than FCL-BB especially over $100 \mathrm{~A}_{\text {peak }}$. Therefore, FCL-BG shows better recovery performance than FCL-BB.

\section{B. Thermal Performance Result}

Fig. 9 shows the changes of the temperatures on the primary coil and the secondary coil. The voltage across the variable autotransformer is $68 \mathrm{~V}_{\mathrm{rms}}$, the inductance of the load reactor is $0 \mathrm{mH}$ and fault time is $0.5 \mathrm{~s}$.

The temperature on the primary coils increased less than $1 \mathrm{~K}$, therefore, the primary coil does not hinder recovery operation.

The temperature on the secondary coils increased more than

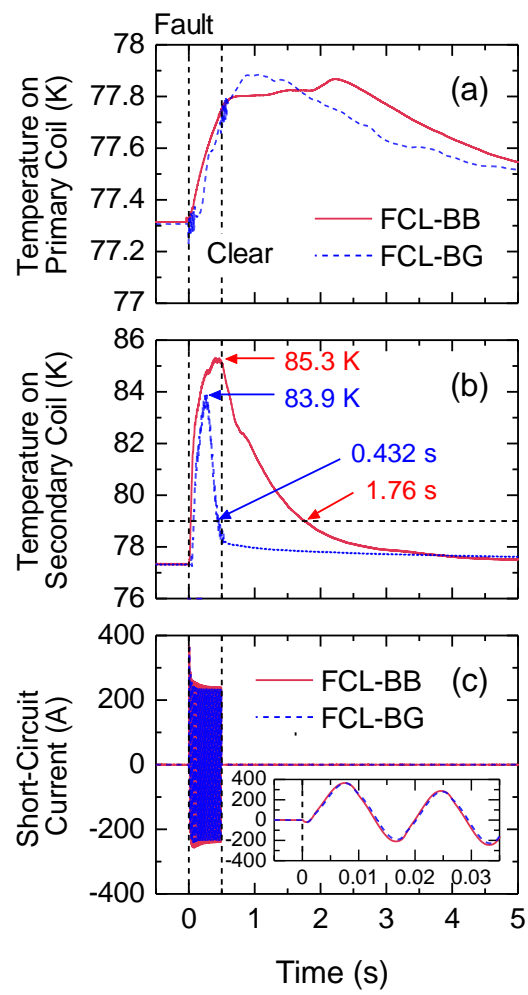

Fig. 9. An example of the experimental results in fault condition. The voltage across the variable autotransformer is $68 \mathrm{~V}_{\mathrm{rms}}$, the inductance of the load reactor is $0 \mathrm{mH}$, and fault time is $0.5 \mathrm{~s}$. (a) the temperature on the primary coil. (b) the temperature on the secondary coil. (c) the short-circuit current through the circuit.

that on the primary coils. The maximum temperature on the secondary coil of FCL-BG $(83.9 \mathrm{~K})$ is lower than that of FCL$\mathrm{BB}(85.3 \mathrm{~K})$. In addition, the time required to cool down to $79 \mathrm{~K}$ on the secondary coil of FCL-BG $(0.432 \mathrm{~s})$ is shorter than that of FCL-BB (1.76 s).

Furthermore, dissipated energy of FCL-BG (747 J) is lower than that of FCL-BB (1212 J).

These results indicate that FCL-BG shows better recovery performance than FCL-BB.

\section{CONCLUSION}

We fabricated two transformer type SFCLs using different HTS wires (BSCCO or GdBCO) for the secondary coils and compared their current limiting characteristics.

The SFCL using the GdBCO wire for the secondary coil (FCL-BG) has more limiting reactance than the SFCL using the BSCCO wire for the secondary coil (FCL-BB). This is because the ratio $R_{2} / L_{2}$ of FCL-BG is larger and the current through the secondary coil of FCL-BG is less induced. In addition, FCL-BG dissipates less energy and the temperature of FCL-BG rises less than that of FCL-BB. Therefore, FCLBG limits the short-circuit current more effectively and recovers to steady-state condition more quickly than FCL-BB.

\section{REFERENCES}

[1] R. Dommerque, S. Krämer, A. Hobl, R. Böhm, M. Bludau, J. Bock, D. Klaus, H. Piereder, A. Wilson, T. Krüger, G. Pfeiffer, K. Pfeiffer, and S. 
Elschner, "First commercial medium voltage superconducting faultcurrent limiters: production, test and installation," Supercond. Sci. Technol., vol. 23, no. 3, pp. 034020, Mar. 2010.

[2] L. Martini, M. Bocchi, M. Ascade, a Valzasina, V. Rossi, C. Ravetta, and G. Angeli, "The first Italian Superconducting Fault Current Limiter: Results of the field testing experience after one year operation," J. Phys. Conf. Ser., vol. 507, no. 3, pp. 032003, May 2014.

[3] Y. Xin, W. Z. Gong, Y. W. Sun, J. B. Cui, H. Hong, X. Y. Niu, H. Z. Wang, L. Z. Wang, Q. Li, J. Y. Zhang, Z. Q. Wei, L. Liu, H. Yang, and X. H. Zhu, "Factory and Field Tests of a 220 kV/300 MVA Statured Iron-Core Superconducting Fault Current Limiter," IEEE Trans. Appl. Supercond., vol. 23, no. 3, pp. 5602305, Jun. 2013.

[4] M. Noe and M. Steurer, "High-temperature superconductor fault current limiters: concepts, applications, and development status," Supercond. Sci. Technol., vol. 20, no. 3, pp. R15-R29, Mar. 2007.

[5] B. Gromoll, G. Ries, W. Schmidt, H.-P. Kramer, P. Kummeth, H.-W. Neumuller, and S. Fischer, "Resistive current limiters with YBCO films," IEEE Trans. Appl. Supercond., vol. 7, no. 2, pp. 828-831, Jun. 1997.

[6] W. Paul, T. Baumann, J. Rhyner, and F. Platter, "Tests of $100 \mathrm{~kW}$ High$\mathrm{T}_{\mathrm{c}}$ superconducting fault current limiter," IEEE Trans. Appl. Supercond., vol. 5, no. 2, pp. 1059-1062, Jun. 1995.

[7] J. Kozak, M. Majka, S. Kozak, and T. Janowski, "Design and Tests of Coreless Inductive Superconducting Fault Current Limiter," IEEE Trans. Appl. Supercond., vol. 22, no. 3, pp. 5601804, Jun. 2012.

[8] O. Naeckel and M. Noe, "Design and Test of an Air Coil Superconducting Fault Current Limiter Demonstrator," IEEE Trans. Appl. Supercond., vol. 24, no. 3, pp. 5601605, Jun. 2014.

[9] Y. Shirai, T. Nii, S. Oda, and M. Shiotsu, "Current limiting characteristics of transformer type HTS superconducting fault current limiter with rewound structure," J. Phys.: Conf. Ser., vol. 234, no. 3, pp. 032053, Jun. 2010.

[10] Y. Shirai, S. Noda, K. Yamabe, K. Hattori, J. Baba, S. Kobayashi, and K. Sato, "Current limiting performance test of 3-phase tri-axial transformertype SFCL with re-wound structure at 3-line-to-ground fault in lab-scale transmission system," Phys. C, Supercond., vol. 484, no. 3, pp. 248-252, Jan. 2013.

[11] Y. Shirai, S. Noda, K. Yamabe, K. Hattori, J. Baba, T. Nishihara, T. Nitta, S. Kobayashi, and K. Sato, "Current Limiting Performance of Three-Phase Concentric Transformer Type SFCL at Unbalanced Fault Conditions," IEEE Trans. Appl. Supercond., vol. 23, no. 3, pp. 5601905, Jun. 2013. 